\title{
The Effects of Thermohaline Circulation on Wind-Driven Circulation in the South China Sea
}

\author{
GUIHUA WANG \\ State Key Laboratory of Satellite Ocean Environment Dynamics, Second Institute of Oceanography, State \\ Oceanic Administration, Hangzhou, China \\ RUI XIN HUANG \\ Woods Hole Oceanographic Institution, Woods Hole, Massachusetts \\ JILAN SU AND DAKE CHEN \\ State Key Laboratory of Satellite Ocean Environment Dynamics, Second Institute of Oceanography, State \\ Oceanic Administration, Hangzhou, China
}

(Manuscript received 30 November 2011, in final form 30 August 2012)

\section{ABSTRACT}

The dynamic influence of thermohaline circulation on wind-driven circulation in the South China Sea (SCS) is studied using a simple reduced gravity model, in which the upwelling driven by mixing in the abyssal ocean is treated in terms of an upward pumping distributed at the base of the upper layer.

Because of the strong upwelling of deep water, the cyclonic gyre in the northern SCS is weakened, but the anticyclonic gyre in the southern SCS is intensified in summer, while cyclonic gyres in both the southern and northern SCS are weakened in winter. For all seasons, the dynamic influence of thermohaline circulation on wind-driven circulation is larger in the northern SCS than in the southern SCS. Analysis suggests that the upwelling associated with the thermohaline circulation in the deep ocean plays a crucial role in regulating the wind-driven circulation in the upper ocean.

\section{Introduction}

The oceanic general circulation is a very complicated dynamic system because it consists of many interacting components. In the past, the common practice was to study these components in isolation. As a result, for a long time the theories of wind-driven circulation, thermohaline circulation, and tides were developed as independent dynamic entities with no interactions between components. For example, the upper ocean circulation is often thought to be wind-driven, excluding the potential impacts of thermohaline circulation and tides.

The first attempt to combine the theories of winddriven and thermohaline circulation can be traced back

Corresponding author address: Guihua Wang, State Key Laboratory of Satellite Ocean Environment Dynamics, Second Institute of Oceanography, State Oceanic Administration, Hangzhou, Zhejiang 310012, China.

E-mail: guihua_wanggh@yahoo.com.cn to the pioneering work of Luyten and Stommel (1986). The basic idea is as follows. Wind-driven circulation in the upper ocean can be understood in terms of the compression or stretching due to Ekman pumping and abyssal or thermohaline circulation can be linked to a deep-water source. The continuity of water masses in the deep ocean requires an upwelling of deep water into the upper ocean, which can be treated as a distributed source that compresses the upper layer. Thus, the upwelling of deep water associated with the thermohaline circulation can play a role similar to that of wind stress-induced Ekman pumping.

Luyten and Stommel (1986) provided a theoretical framework for the interaction between wind-driven and thermohaline circulation, which was followed by Pedlosky (1986), Hautala and Riser (1989), and Huang (1993), among others. However, these studies did not show any major impact of the thermohaline circulation on the upperocean circulation. This seemingly weak interaction may be explained by the following scaling argument. The typical strength of Ekman pumping velocity in the upper ocean is 


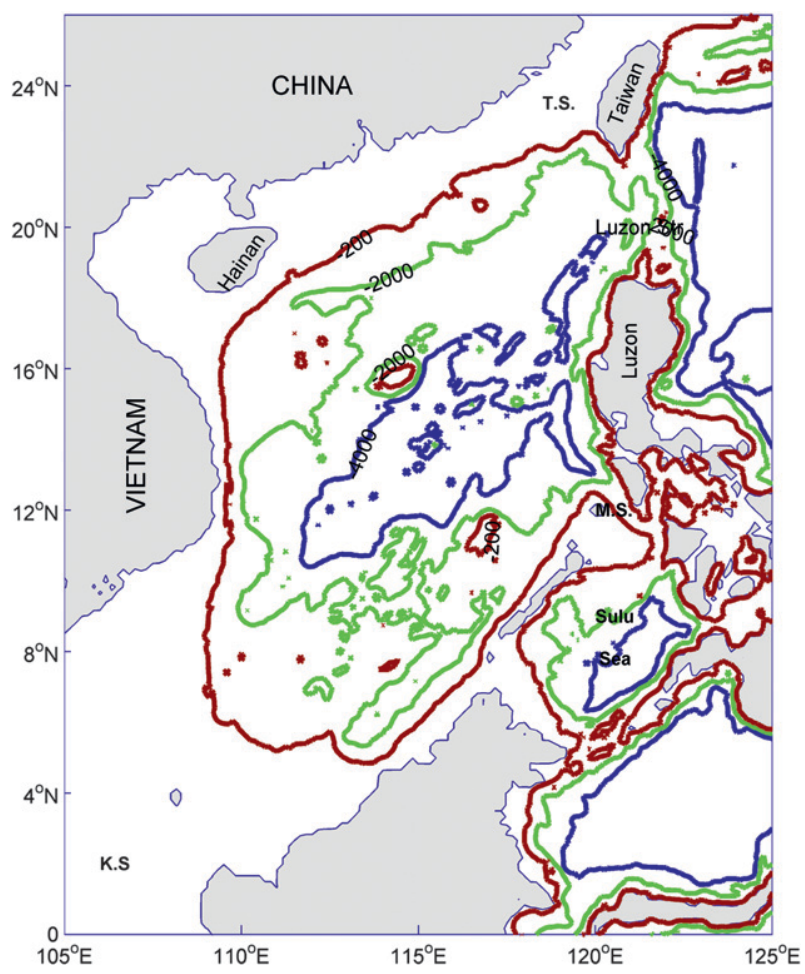

FIG. 1. Map of the SCS. Isobaths are in meters. K.S.: Kalimantan Strait; T.S.: Taiwan Strait.

on the order of $10^{-6} \mathrm{~m} \mathrm{~s}^{-1}$, while the upwelling velocity from the abyss is much weaker. Except for narrow upwelling bands, the upwelling rate below the main thermocline is on the order of $10^{-7} \mathrm{~m} \mathrm{~s}^{-1}$. Thus, the impact of deep-water upwelling in the open ocean is a relatively small contributor; for many applications, circulation in the open ocean can be examined in terms of a pure winddriven circulation with acceptable errors.

However, for some special regions of the world oceans, the deep water renewal rate and the corresponding upwelling rate may be much larger; thus the interaction between wind-driven and thermohaline circulation may be much stronger. The SCS may offer the best example for such cases. The SCS is a large, deep, semienclosed marginal sea in the northwestern Pacific (Fig. 1). The width of the SCS is on the order of $1000 \mathrm{~km}$ and the average water depth is $2000 \mathrm{~m}$ with the maximum depth around $5560 \mathrm{~m}$. Many features of the SCS circulation are similar to those in open oceans (e.g., Wyrtki 1961; Qu 2000; Liu et al. 2001). There is strong wind stress forcing at the surface, deepwater overflow through the Luzon Strait, along with complicated and rough topography. The rich dynamics in the SCS make it a good test bed for key dynamic processes that are important throughout the world oceans.

The SCS circulation has been studied by separating the circulation into two parts, that is, a wind-driven circulation in the upper $1000 \mathrm{~m}$ and a thermohaline circulation in the deep part of the basin.

As characterized by the $20^{\circ} \mathrm{C}$ isotherm (Fig. 2) from Generalized Digital Environment Model (GDEM, Carnes 2009), the upper-layer SCS circulation is generally a cyclonic gyre during the winter monsoon period, while it splits into a cyclonic gyre north of about $12^{\circ} \mathrm{N}$ and an anticyclonic gyre south of it during the summer monsoon period. In most previous studies, the upper SCS circulation has been regarded as purely driven by the seasonal forcing of the East Asian monsoon, without considering the potential contribution from the deep ocean.

On the other hand, the thermohaline circulation in the deep part of the SCS is characterized by a basin scale, western intensified cyclonic gyre, as evident in temperature, salinity, sediment and oxygen observations (Broecker et al. 1986; Qu et al. 2006; Wang et al. 2011). Because of the presence of many shallow areas and geometry of landsea distribution, tidal circulation and associated dissipation are strong within the SCS. A sill at a depth of $2.2 \mathrm{~km}$ in the Luzon Strait enables a deep-water overflow from the open Pacific into the SCS. It is estimated that the Luzon Strait overflow imports about $2-3 \mathrm{~Sv}\left(1 \mathrm{~Sv} \equiv 10^{6} \mathrm{~m}^{3} \mathrm{~s}^{-1}\right)$ deep water from the Pacific (Qu et al. 2006; Tian et al. 2006).

Because of the strong tidal mixing over rough topography in the SCS, the deep-water renewal rate in the SCS is quite fast. The mean upwelling rate over this relatively small basin is on the order of $10^{-6} \mathrm{~m} \mathrm{~s}^{-1}$, which is comparable to the typical magnitude of Ekman pumping. Thus, the upwelling associated with the overflow through the Luzon Strait can reach the upper layer (Cardona and Bracco 2012), and may be a nonnegligible component of the driving force for the upper SCS circulation.

The goal of this study is to understand the effect of the thermohaline circulation on the wind-driven circulation in the SCS with a simple reduced gravity model. This paper is organized as follows. We first present the simple model in section 2. The dynamical role of the thermohaline circulation on the upper layer circulation and the associated western boundary transport is explored in section 3 . Finally, conclusions and discussion are given in section 4 .

\section{Model}

\section{a. Reduced gravity model}

To explore the basic interaction between the winddriven gyres in the upper ocean and the thermohaline circulation over the whole depth of the water column, the ocean is separated into two layers: an upper layer for the wind-driven circulation, and the lower layer for the deep part of the circulation. Our main focus is on the 

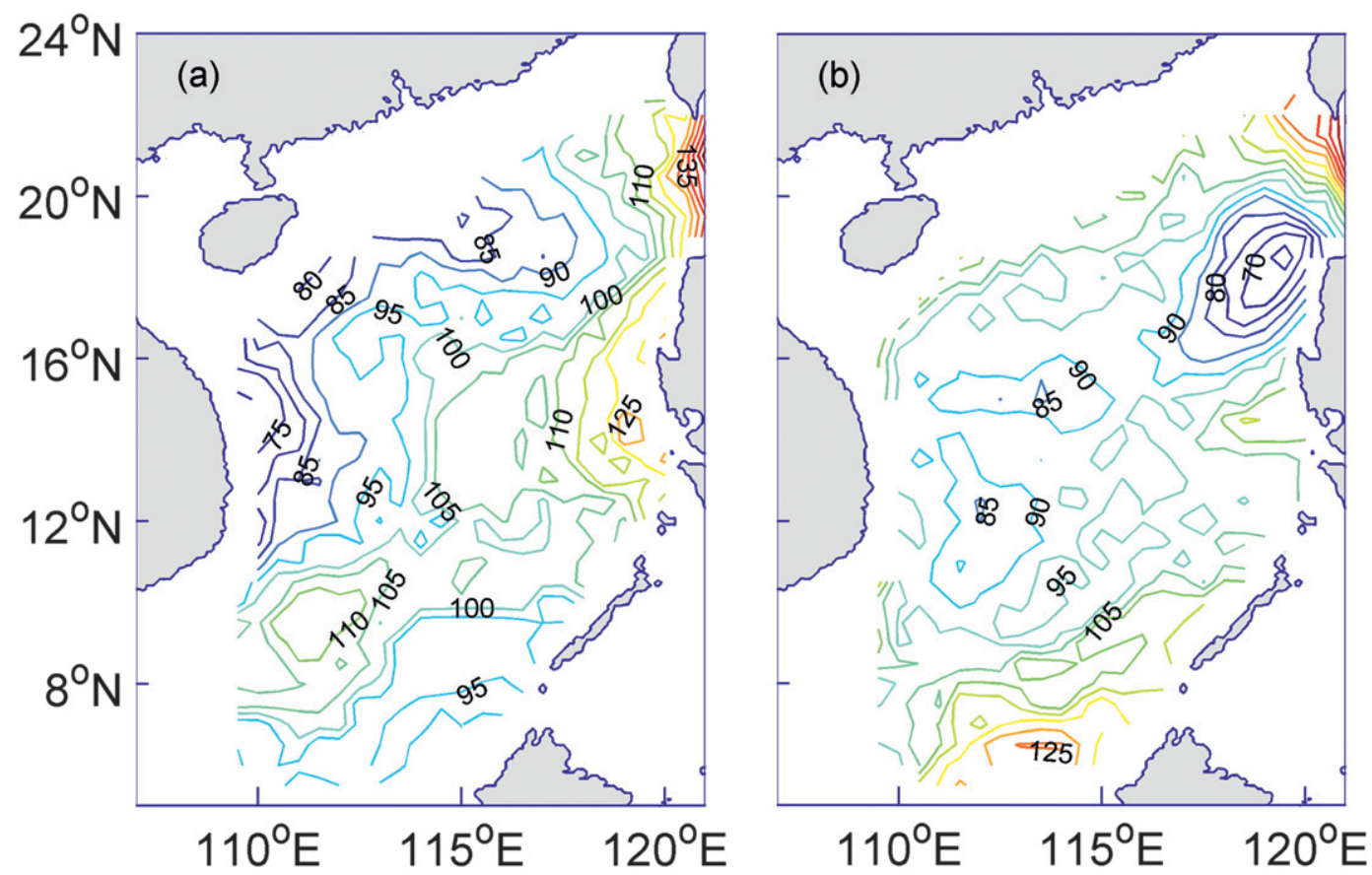

FIG. 2. Climatological isotherm depth (m) of $20^{\circ} \mathrm{C}$ from GDEM for (a) summer and (b) winter.

motion of the upper layer, therefore we neglect the pressure gradient in the lower layer, which leads to the formulation of a one-and-a-half layer, reduced gravity model.

For further simplicity, we only consider quasi-steady circulation in the SCS. In the northern part of the SCS, the basin-crossing time for the first mode Rossby wave is about 3 months. The corresponding time is even shorter in the other parts of the SCS. Thus, the assumption of a quasi-steady state is marginally applicable. The formulation of linear reduced gravity model follows the commonly used approach (Huang 2010).

Omitting the time dependent terms, the inertial terms and the friction, the momentum equations in a reduced gravity model are reduced to

$$
\begin{gathered}
-f h v=-g^{\prime} h h_{x}, \quad \text { and } \\
f h u=-g^{\prime} h h_{y},
\end{gathered}
$$

where $f$ is the Coriolis parameter, $h$ the upper-layer thickness, $(u, v)$ the horizontal velocity of the upper layer, and $g^{\prime}$ the reduced gravity. The continuity equation is

$$
(h u)_{x}+(h v)_{y}=-w_{e}+w_{b}
$$

the Ekman pumping rate is related to the wind stress through

$$
w_{e}=\frac{\partial}{\partial x}\left(\frac{\tau^{y}}{\rho_{0} f}\right)-\frac{\partial}{\partial y}\left(\frac{\tau^{x}}{\rho_{0} f}\right),
$$

where $\left(\tau^{x}, \tau^{y}\right)$ are the wind stress components, $\rho_{0}=$ $1026 \mathrm{~kg} \mathrm{~m}^{-3}$ is the constant reference density. Here, $w_{b}$ is the diapycnal velocity across the lower surface of the upper layer, which is induced by diapycnal mixing in the deep ocean sustained by sources of external mechanical energy. In most previous studies of circulation in the SCS, the contribution of this term has been overlooked, and the specification of this term will be discussed in detail in the following section.

Cross-differentiating (1) and (2) and using the continuity Eq. (3) lead to the vorticity equation

$$
\beta h v=f\left(w_{e}-w_{b}\right),
$$

where $\beta$ is the meridional gradient of the Coriolis parameter. The most important point of Eq. (5) is that the diapycnal velocity induced by mixing in the abyssal ocean can directly affect the wind-driven circulation, as illustrated in the pioneering work of Luyten and Stommel (1986).

Substituting Eq. (5) into Eq. (1) and zonally integrating lead to the equation governing the upper layer thickness

$h^{2}(x, y)=h_{e}^{2}-\frac{2 f^{2}}{\beta g^{\prime}} \int_{x}^{x_{e}}\left[w_{e}\left(x^{\prime}, y\right)-w_{b}\left(x^{\prime}, y\right)\right] d x^{\prime}$, 
where $h_{e}$ is the layer thickness along the eastern boundary of the basin, and under the framework of a reduced gravity model, this is assumed to be a constant independent of time and the meridional coordinate; $x$ and $y$ are the zonal and meridional coordinates; $x_{e}$ is the eastern boundary of the ocean basin.

Since there are sources of water coming from below, the horizontal flow field in the moving layer cannot be described in terms of a streamfunction alone. Starting from the eastern boundary and zonally integrating the meridional velocity gives rise to the meridional volume flux rate, or the generalized Sverdrup function:

$$
m(x, y)=-\frac{f}{\beta} \int_{x}^{x_{e}}\left[w_{e}\left(x^{\prime}, y\right)-w_{b}\left(x^{\prime}, y\right)\right] d x^{\prime} .
$$

The choice of $h_{e}$ is not unique. In this study we set $h_{e}$ of the SCS to $200 \mathrm{~m}$. Such a choice is somewhat arbitrary, but it represents the mean stratification in the SCS fairly well (Liu et al. 2001; Cai et al. 2002).

According to Eqs. (6) and (7), the squared layer thickness and the generalized Sverdrup function are proportional to the factor $f^{2} / \beta$ and $f / \beta$, respectively. Since the SCS extends from low latitudes (around $5^{\circ} \mathrm{N}$ ) to middle latitudes (around $25^{\circ} \mathrm{N}$ ), the factors $f^{2} / \beta$ and $f / \beta$ vary greatly. Because $f$ increases northward, but $\beta$ is slightly reduced with increasing latitude, the wind-driven circulation tends to be stronger on the poleward side of the gyre. This phenomenon is sometimes called the northern intensification, and it can be identified from hydrographic data. In traditional wind-driven models, the upper layer is isolated from the thermohaline circulation in the deeper part of the ocean. Technically, in such models there is no mass flux across the base of the upper layer. The model used in this study, however, includes the dynamical effect of the upwelling from the deeper part of the ocean.

\section{b. Determination of the abyssal vertical velocity distribution}

In the classical theory of deep circulation postulated by Stommel and Arons (1960), the abyssal upwelling is assumed uniform over the entire basin. However, observations suggest that upwelling is nonuniform (Whitworth et al. 1999). Because the upwelling velocity is too small to measure directly, it has been estimated by various indirect means (Kuo and Veronis 1973; Stuiver et al. 1983; Robbins and Toole, 1997). In this study, vertical velocity is calculated by two different methods. First, we assume that vertical mixing in the abyss is sustained by tidal dissipation, thus the vertical velocity can be calculated by assuming a one-dimensional balance of density in the vertical direction; Second, the velocity field in the oceanic interior is closely linked to the density field, thus the vertical velocity in the deep basin can be estimated from the P-vector method (Chu, 1995). More details of these two methods are discussed below.

Thermohaline circulation in the ocean is regulated by two major categories of forcing. First, external sources of mechanical energy are crucial for sustaining the diapycnal mixing and thus the thermohaline circulation. Second, the surface buoyancy forcing sets up the meridional difference in surface density, and thus regulates the thermocline circulation. Base on the energy constraint and buoyancy constraint, Guan and Huang (2008) postulated that the abyssal upwelling can be parameterized as

$$
w_{b}=\frac{e}{g^{\prime} D}
$$

where $e$ is the source of external mechanical energy for a water column with unit horizontal area, and $D$ is the scale depth of the main thermocline. In this study, the $20^{\circ} \mathrm{C}$ isotherm from the GDEM data is taken as the main thermocline in the SCS, and $g^{\prime}$ is the reduced gravity defined by the density difference between the upper part and low part of $20^{\circ} \mathrm{C}$ isotherm depth calculated from the GDEM data.

Over the past decade, our understanding of the energetics of the oceanic general circulation has progressed rapidly. It is now commonly accepted that tidal dissipation and wind stress are the two main sources of mechanical energy sustaining diapycnal mixing in the ocean. Most of the tidal energy dissipates in the shallow parts of the ocean, thus leaving a small portion of the tidal dissipation occurring in the deep ocean.

Recent studies indicate that tidal dissipation in the deep ocean can be substantially enhanced in the vicinity of rough topography where a large amount of barotropic tidal energy is converted into internal tides; internal waves break and diapycnal mixing ensure. The topographyinduced strong mixing can be parameterized in terms of the energy lost by the barotropic tide to internal waves. A concise formulation was postulated by Jayne and St. Laurent (2001). Accordingly, the tidal energy dissipation can be calculated as follows:

$$
E_{\text {tide }}=\iint_{A} 0.5 g \rho_{0} k h^{2} N u^{2} d x d y,
$$

where $u$ is the averaged horizontal speed of the barotropic tides over a tidal cycle, $N$ is the buoyancy frequency, $k=2 \pi / 1.0 \times 10^{4}$ is the wavenumber, and $h$ is the amplitude that characterizes the bathymetry computed according to the formulae by Jayne and St. Laurent (2001). In this study, we use $1 / 12^{\circ}$ ocean topography database, thus taking horizontal scales of $O\left(10^{4} \mathrm{~m}\right)$ as typical of the roughness is optimal. 

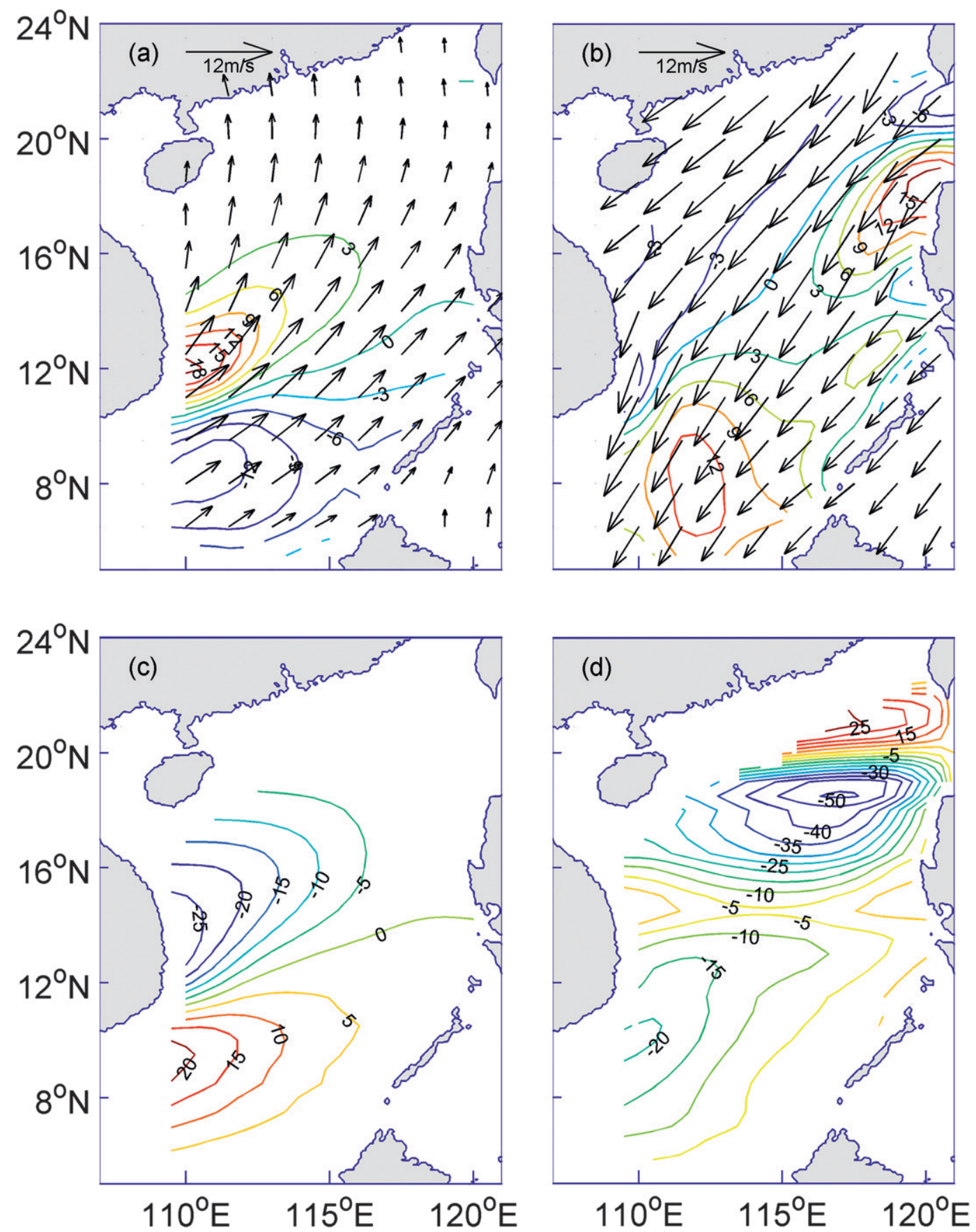

FIG. 3. (a) Summer- and (b) winter-averaged Quick Scatterometer (QuikSCAT) wind vector ( $\mathrm{m} \mathrm{s}^{-1}$ ) and Ekman pumping velocity $\left(\times 10^{-6} \mathrm{~m} \mathrm{~s}^{-1}\right.$, color contour); (c) summer and (d) winter thermocline depth anomaly (m) driven by Ekman pumping only.

Wind stress, including seasonal monsoons and typhoons, can provide additional source of mechanical energy sustaining thermocline circulation, including the energy input to surface waves, and surface currents. These two sources of energy can be estimated by empirical formulas (Wang and Huang 2004a,b). Although wind energy input to the ocean is quite large, its link to diapycnal mixing in the subsurface ocean remains unclear; thus, we leave these two sources of mechanical energy for future exploration, and focus on the role of tide dissipation as the only source of external mechanical energy to sustain diapycnal mixing. 
Vertical velocity in the deep ocean can also be estimated from a quite different approach. Pedlosky (1986) pointed out that the three-dimensional velocity field can be determined from knowledge of the density. Based on the conservation of potential density and potential vorticity, the vertical velocity can be determined by the P-vector method. This method is chosen because it can simulate both the upper layer circulation and deep circulation in the SCS well and it has a capability to diagnose the vertical velocity (Chu 1995; Chu and Wang 2003).

\section{c. Numerical experiments}

In the following section, we will evaluate the dynamic effect of the thermohaline circulation on the winddriven circulation in the upper part of the SCS through three experiments:

case 1: circulation driven by Ekman pumping only;

case 2: circulation driven by Ekman pumping, plus uniform upwelling from the deep ocean driven by the Luzon Strait overflow; and

case 3: circulation driven by Ekman pumping, plus nonuniform upwelling from the deep ocean, with the corresponding vertical velocity estimated from tidal dissipation or the P-vector method.

To extract the essential part of the wind-driven circulation which is independent of the choice of the thermocline depth along the eastern boundary, we will plot the layer thickness deviation from that along the eastern boundary, that is, in most figures we plot $h-h_{e}$ instead of $h$.

\section{Results}

\section{a. Thermocline depth subject to Ekman pumping alone}

As a part of the East Asian monsoon system, the surface wind in the SCS has a strong seasonal cycle (Figs. 3a and $3 b)$. From June to August, the summer southwesterly wind prevails in the SCS. On average, the seasonal transition from the southwest monsoon to northeast occurs in September. From October to March, the atmospheric circulation in the SCS is controlled by the northeasterly monsoon, which is generally stronger than the summer monsoon.

Figure 3 also shows the climatological distribution of Ekman pumping velocity derived from QuikSCAT wind. In summer, the Ekman upwelling and downwelling prevails in the northern and southern parts, respectively; this pattern of Ekman pumping is associated with the wind jet at about $10^{\circ} \mathrm{N}$ off central Vietnam (Xie et al. 2003). During winter, there is Ekman upwelling in the southeastern SCS and Ekman downwelling in the northwestern SCS; this pattern is attributed to the wind jet through the Luzon
TABLE 1. Mean vertical velocity $\left(\times 10^{-6} \mathrm{~m} \mathrm{~s}^{-1} ; W_{e}\right.$ is Ekman pumping; $W_{b}$ is the vertical velocity at the thermocline base).

\begin{tabular}{|c|c|c|c|c|c|}
\hline \multicolumn{2}{|c|}{ Summer $W_{e}$} & \multicolumn{2}{|c|}{ Winter $W_{e}$} & \multicolumn{2}{|c|}{$W_{b}$} \\
\hline Positive & Negative & Positive & Negative & $\begin{array}{l}\text { Luzon } \\
\text { overflow }\end{array}$ & $\begin{array}{c}\text { Internal } \\
\text { tides }\end{array}$ \\
\hline 2.54 & -6.20 & 6.33 & -2.84 & 2.10 & 2.08 \\
\hline
\end{tabular}

Strait (Wang et al. 2008). Because of the strong monsoon, Ekman pumping rate in the SCS is rather high. The average Ekman pumping velocity in these two seasons is listed in Table 1. The maximum Ekman pumping velocity can reach 18.98 and 17.72. (13.70 and 7.76) $\left(\times 10^{-6} \mathrm{~m} \mathrm{~s}^{-1}\right)$ for the upwelling and downwelling in summer (winter), respectively.

As the first step, we assume that the wind-driven circulation in the SCS is a quasi-steady response to the Ekman pumping. Figures $3 \mathrm{c}$ and $3 \mathrm{~d}$ show the mean thermocline depth anomaly (defined as the deviation from $200 \mathrm{~m}$ ) driven by Ekman pumping only. In summer, the largescale cyclonic gyre in the northern SCS and the anticyclonic gyre in the southern SCS are clearly evident (Fig. 3c). In winter, the northeasterly monsoon drives a grand basin-wide cyclonic flow, which consists of two subgyres: the northern SCS gyre and the southern SCS gyre (Fig. 3d). Note that the squared layer thickness is proportional to a factor $f^{2} / \beta$, thus response of the thermocline to the Ekman pumping is enhanced with the increase of latitude. As a result, although the Ekman pumping at $10^{\circ} \mathrm{N}$ north in summer is fairly weak, the thermocline displacement is still large. In addition, there is a small anticyclonic gyre in the northeast part of the SCS, as can be seen from the negative Ekman pumping velocity north of $20^{\circ} \mathrm{N}$. Note that the narrow anticyclonic gyre around $14^{\circ} \mathrm{N}$ between these two gyres may be illusive (Wang et al. 2009).

The model-simulated thermocline depth is generally consistent with the observed one derived from GDEM. The spatial correlation coefficients between them are 0.28 and 0.32 for summer and winter, respectively. The consistency in pattern indicates that the basic feature of wind driven circulation in the upper part of the SCS can be simulated by our linear reduced gravity model, but the relatively small value of correlation coefficient also suggests that other dynamic processes, such as thermohaline circulation, may contribute to the upper layer circulation.

\section{b. Thermocline depth subject to Ekman pumping plus uniform upwelling from abyssal ocean}

The existence of the Luzon Strait overflow can be identified from both observations and model simulations (Qu et al. 2006; Li and Qu 2006; Wang et al. 2011). The 

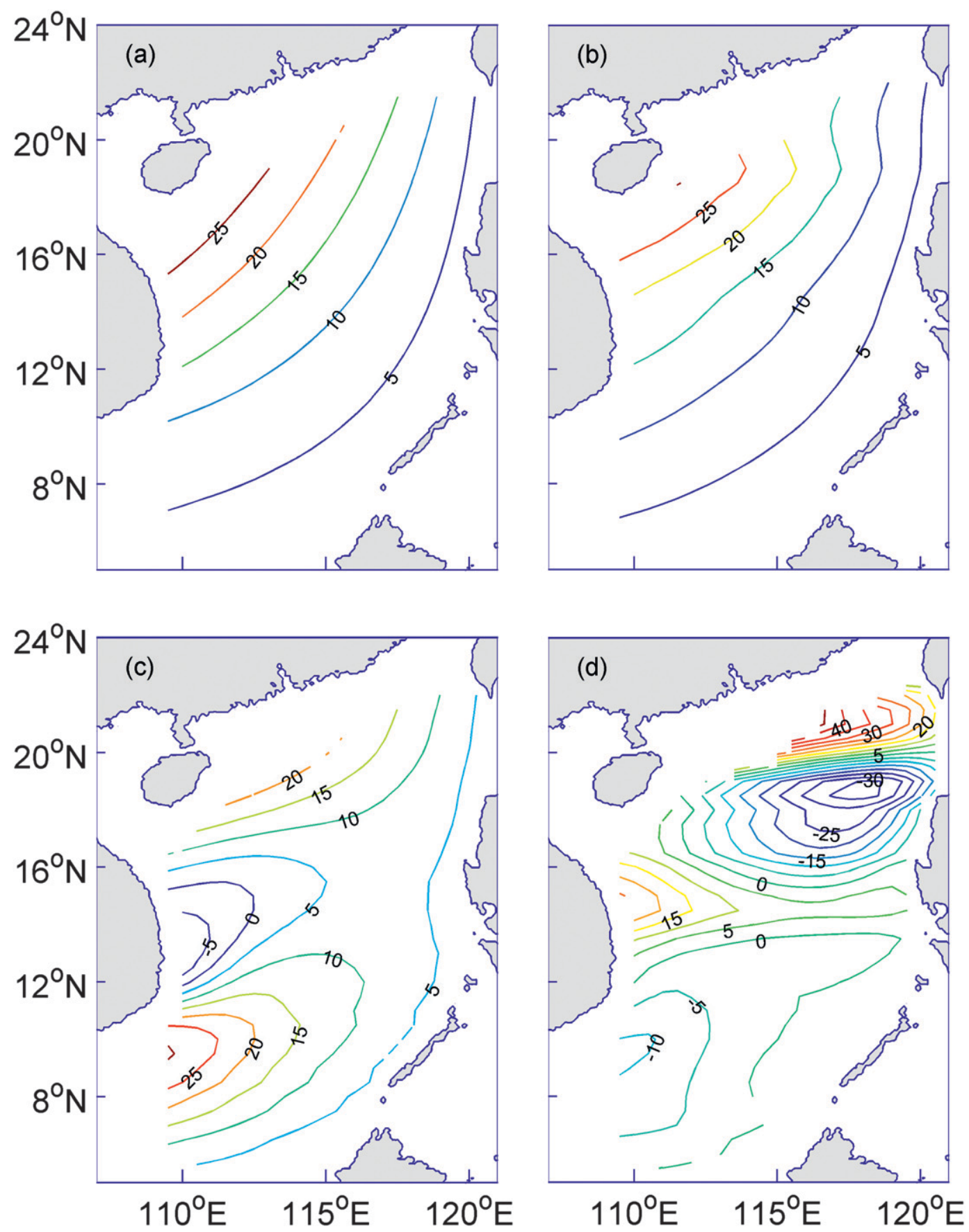

FIG. 4. The difference of thermocline depth (m) between case 2 and case 1 in (a) summer and (b) winter; (c),(d) the thermocline depth anomaly in case 2 for summer and winter, respectively.

Luzon Strait transport from the Pacific to the SCS is estimated to be $0.7-3.0 \mathrm{~Sv}$. The overflow usually is confined below $1350 \mathrm{~m}$ (Tian et al. 2006). The equivalent deep transport through the Luzon Strait in our simple model is estimated from the Simple Ocean Data Assimilation (SODA) data, by integrating zonal velocity from bottom to the thermocline depth $\left(20^{\circ} \mathrm{C}\right.$ isotherm $)$ and from $17.5^{\circ}$ to $23.5^{\circ} \mathrm{N}$ along $120.5^{\circ} \mathrm{E}$. The most important and intrinsic feature of this transport is its strong seasonal cycle, with a maximum $(3.5 \mathrm{~Sv})$ in December and a minimum $(0.7 \mathrm{~Sv})$ in May. The annual mean of the transport is about $2.5 \mathrm{~Sv}$.

A rough estimate of the upwelling velocity is $Q / A$, where $Q$ is the mean Luzon transport below the thermocline, 
TABLE 2. Maximum thermocline depth variability $(\mathrm{m})$, the values in parentheses represent the contribution of the thermohaline circulation to the upper-layer ocean relative to case 1.

\begin{tabular}{llcccr}
\hline \hline & & Case 1 & Case 2 & Case 3a & Case 3b \\
\hline \multirow{2}{*}{ Summer } & North & -28.1 & $-9.6(-65.8 \%)$ & $-22.8(-18.9 \%)$ & $-23.5(-16.3 \%)$ \\
& South & 22.1 & $30.6(38.5 \%)$ & $27.1(18.5 \%)$ & $26.7(20.7 \%)$ \\
\multirow{2}{*}{ Winter } & North & -51.0 & $-35.1(-31.2 \%)$ & $-34.9(-31.6 \%)$ & $-36.9(-27.6 \%)$ \\
& South & -21.0 & $-14.8(-29.5 \%)$ & $-16.8(-20 \%)$ & $-17.1(-18.8 \%)$ \\
\hline
\end{tabular}

and $A$ is the area of the SCS taking at the depth of 200-m isobaths. The choice of 200-m isobaths is consistent with our choice of thermocline thickness along the eastern boundary. Since the SCS is a basin with both positive and negative Ekman pumping, using the mean depth of the thermocline along the eastern boundary seems a reasonable choice.

The estimated upwelling velocity is about $2.1 \times$ $10^{-6} \mathrm{~m} \mathrm{~s}^{-1}$, and it is on the same order as Ekman pumping velocity $\left(2.5 \sim 6.3 \times 10^{-6} \mathrm{~m} \mathrm{~s}^{-1}\right.$, Table 1$)$. This additional upwelling is equivalent to a compression of the upper layer, thus it is an important factor regulating the wind-driven circulation in the upper ocean. It adds on an additional component of the basic solution driven by Ekman pumping alone. This additional interior flow is anticyclonic, and the corresponding anomaly of the western boundary current transport is poleward for both the summer (Fig. 4a) and winter (Fig. 4b) seasons. Note that the additional anticyclonic circulation in the northern SCS is stronger than in the southern SCS because of the factor $f^{2} / \beta$.
The uniform upwelling from abyssal ocean combines with Ekman pumping and thus modifies the wind-driven gyre in the upper ocean. In summer season, the anticyclonic gyre in the southern SCS is intensified and the cyclonic gyre in the northern SCS is weakened (Fig. 4c); while in winter the cyclonic gyres in both southern and northern parts of the SCS are weakened (Fig. 4d). The small anticyclonic gyre north of $20^{\circ} \mathrm{N}$ is intensified. Quantitatively, taking model forced by Ekman pumping alone as a reference, in the summer season the northern cyclonic gyre of the SCS is reduced by about $65.8 \%$ and the southern anticyclonic gyre is intensified by about $38.5 \%$; while in the winter season, the cyclonic gyres in both southern and northern parts of the SCS are reduced by about $30 \%$ (Table 2 ). The spatial correlation coefficients between the simulated thermocline depth and the observed one are 0.33 and 0.37 for summer and winter, respectively. These values are slightly higher than the case of Ekman pumping only, indicating that upwelling associated with the thermocline circulation is a factor regulating the upper-layer circulation.

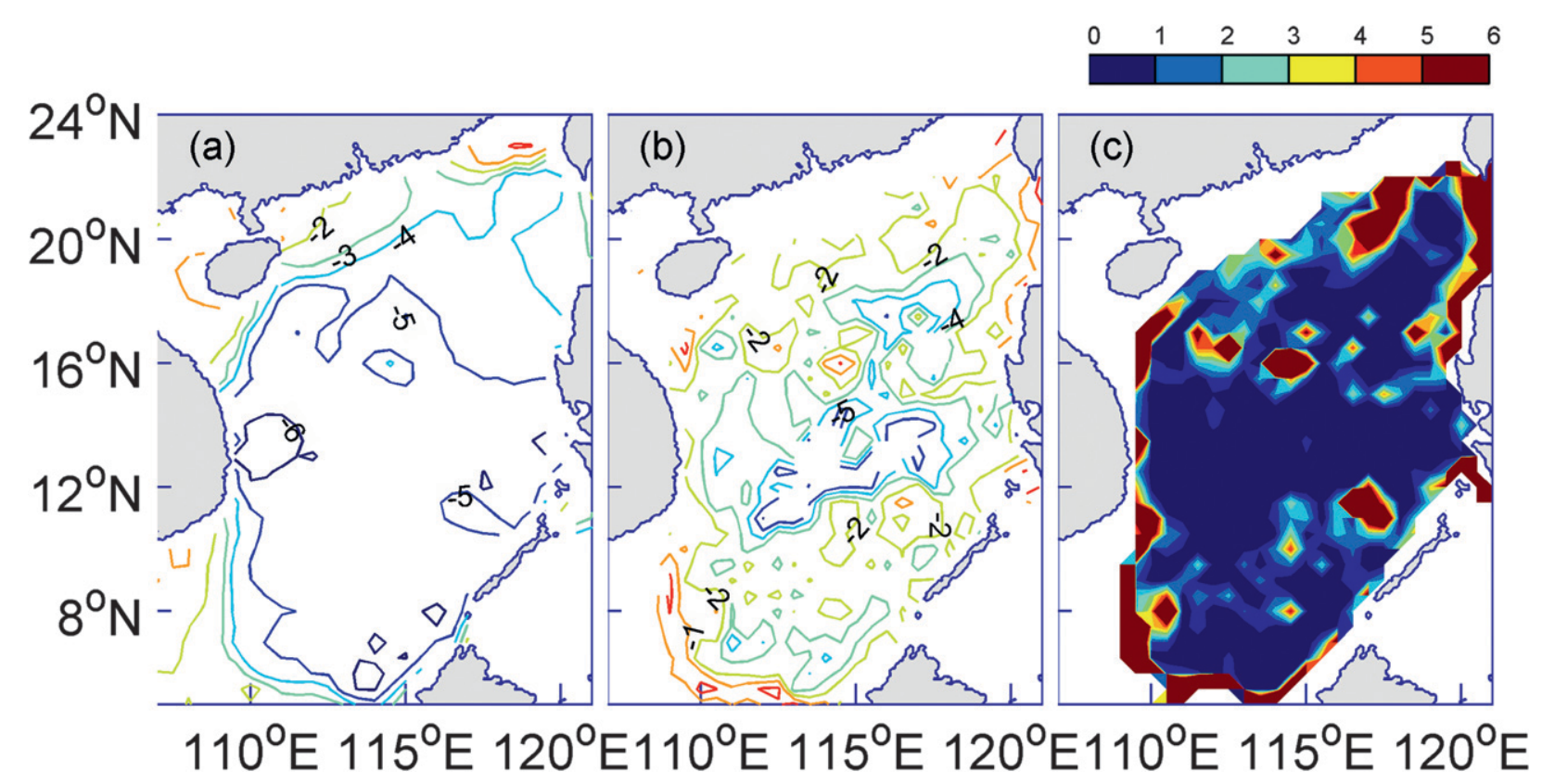

FIG. 5. Tidal energy dissipation $\left(\log _{10} \mathrm{~W} \mathrm{~m}^{-2}\right.$ ) for (a) barotropic model; (b) including the energy transfer from barotropic tide to internal waves; and (c) is the nonuniform upwelling $\left(\times 10^{-6} \mathrm{~m} \mathrm{~s}^{-1}\right)$ derived from tidal dissipation energy (b). 

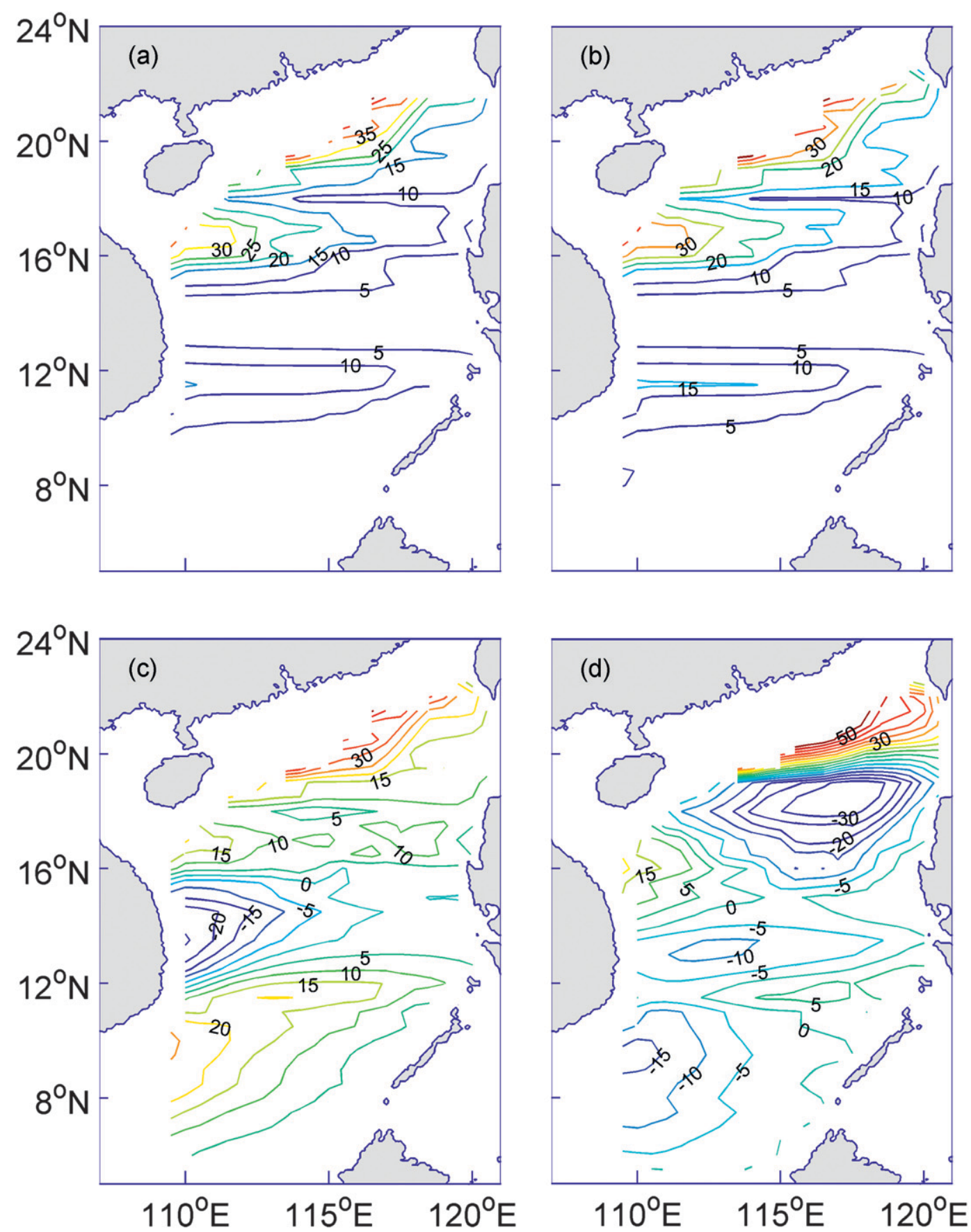

FIG. 6. The difference of thermocline depth (m) between case $3 \mathrm{a}$ and case 1 in (a) summer and (b) winter; (c),(d) the thermocline depth anomaly in case 3 a for summer and winter, respectively.

c. Thermocline depth subject to Ekman pumping plus nonuniform upwelling from the abyssal ocean

The assumption of basin-wide uniform upwelling made in the previous section is highly idealized. There is apparently no a priori reason why upwelling should be basin-wide uniform. As discussed in section 2, the upwelling from the abyssal ocean can be estimated by two methods.

The SCS is characterized by strong tidal dissipation. Because of the relatively small basin size, rough topography, and the opening at the Luzon Strait, there is 


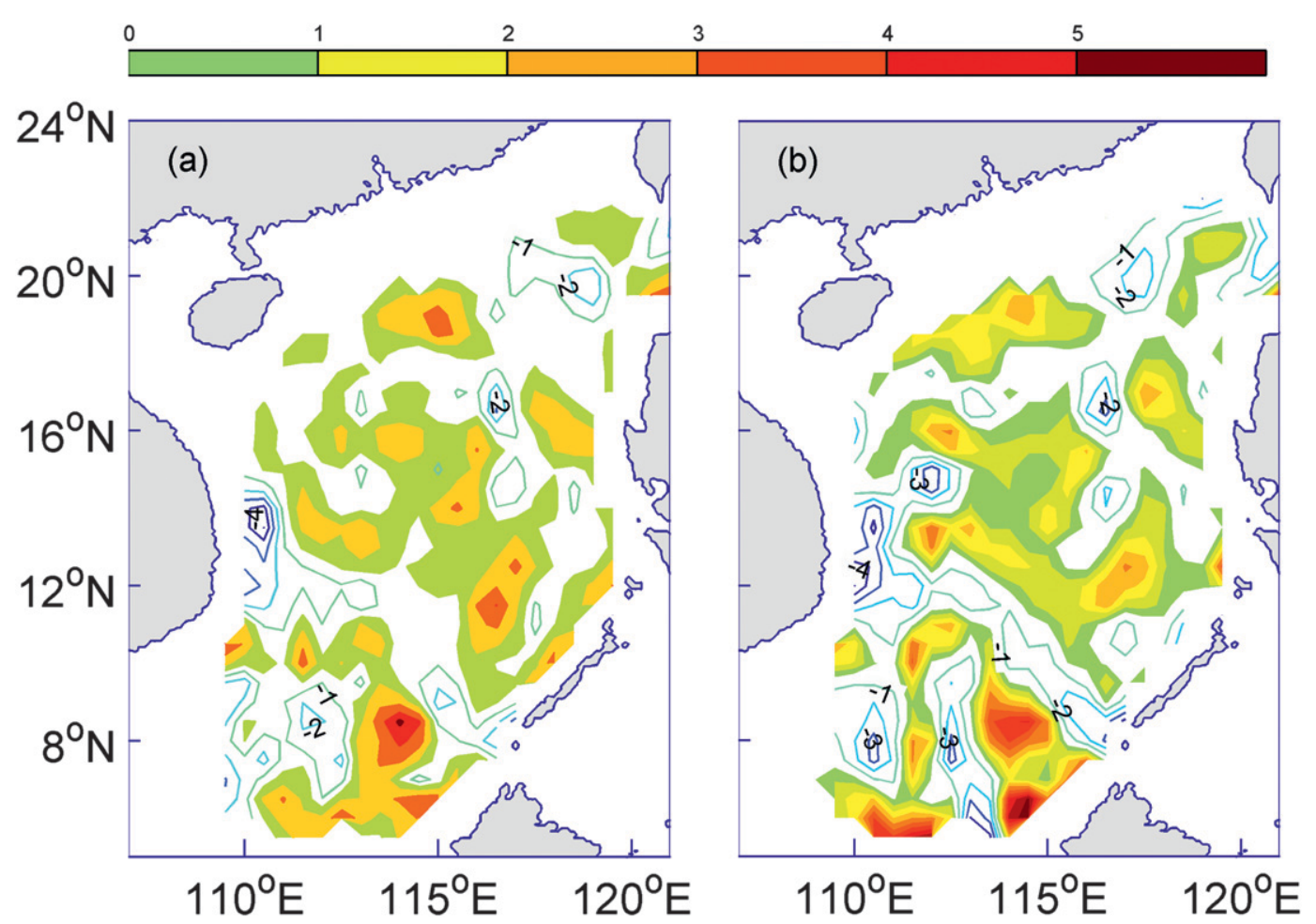

FIG. 7. Vertical velocity $\left(\times 10^{-6} \mathrm{~m} \mathrm{~s}^{-1}\right)$ at the base of the thermocline calculated from P-vector method for (a) summer and (b) winter. The upward velocity is color-shaded.

strong tidal dissipation primarily driven by tidal energy generated in the open Pacific Ocean and imported through the Luzon Strait (Tong et al. 2010). By including four constituents $\left(M_{2}, S_{2}, K_{1}\right.$, and $\left.O_{1}\right)$ in their model, Tong et al. (2010) found that the dissipation of barotropic tides is about $11 \mathrm{GW}$, and that only $0.69 \%$ of the dissipation $(0.07 \mathrm{GW})$ took place in the deep ocean (deeper than $200 \mathrm{~m}$ ). However, there is a large energy conversion from the barotropic tide to internal waves. In this study we will treat the energy lost from the barotropic tide as the apparent dissipation of the barotropic tides. Using Eq. (9), the tidal dissipation in the SCS is estimated at $55.8 \mathrm{GW}$, and the corresponding dissipation in the deep part of the SCS is estimated at $36.4 \mathrm{GW}$, about $65 \%$ of the total apparent dissipation.

Figures $5 \mathrm{a}$ and $5 \mathrm{~b}$ show the spatial distribution of energy dissipation inferred from the model simulations without and with the energy transfers from barotropic tide to internal waves, respectively. The dissipation rate is only about $10^{-5}-10^{-3} \mathrm{~W} \mathrm{~m}^{-2}$ for the case of barotropic tides alone; while it is about $10^{-3}-10^{-1} \mathrm{~W} \mathrm{~m}^{-2}$ for the case including energy conversion from the barotropic to internal tides. Our estimation for the SCS tidal dissipation is consistent with the results obtained by Jayne and St. Laurent (2001). The enhanced dissipation rate also compares favorably with the diapycnal mixing from direct microstructure measurements in the SCS (Tian et al. 2009). Because of the spatial distribution of bottom topography, strong dissipation in the deep part of the SCS appears in forms of three bands where the topography is very rough. These three bands lie 1) along the continental shelf in the northern SCS, 2) along the continental shelf in the southeastern SCS, and 3) along a zonal band around $16^{\circ} \mathrm{N}$ from the west of Luzon Island to east of Vietnam.

Suppose the abyssal upwelling is induced by tidal mixing only and other processes, such as propagation of nonlinear solitary internal waves, are omitted. It is readily seen that upwelling is strong in the three bands listed above (Fig. 5c). With the upwelling induced by tides, there is a strong additional anticyclonic circulation component in the northern SCS and a weaker one around $12^{\circ} \mathrm{N}$ in the southern SCS for both summer (Fig. 6a) and winter (Fig. 6b) seasons. The northern one is associated with the two northern bands where the upwelling is strong; the southern one is related to the band along the continental shelf in the southeastern SCS. Compared with the circulation forced by Ekman pumping only, the additional anticyclonic circulation intensifies the anticyclonic gyre in the southern SCS by $18.5 \%$ and weakens the cyclonic gyre in the northern SCS by about $18.9 \%$ in summer (Fig. 6c, also see Table 2), 

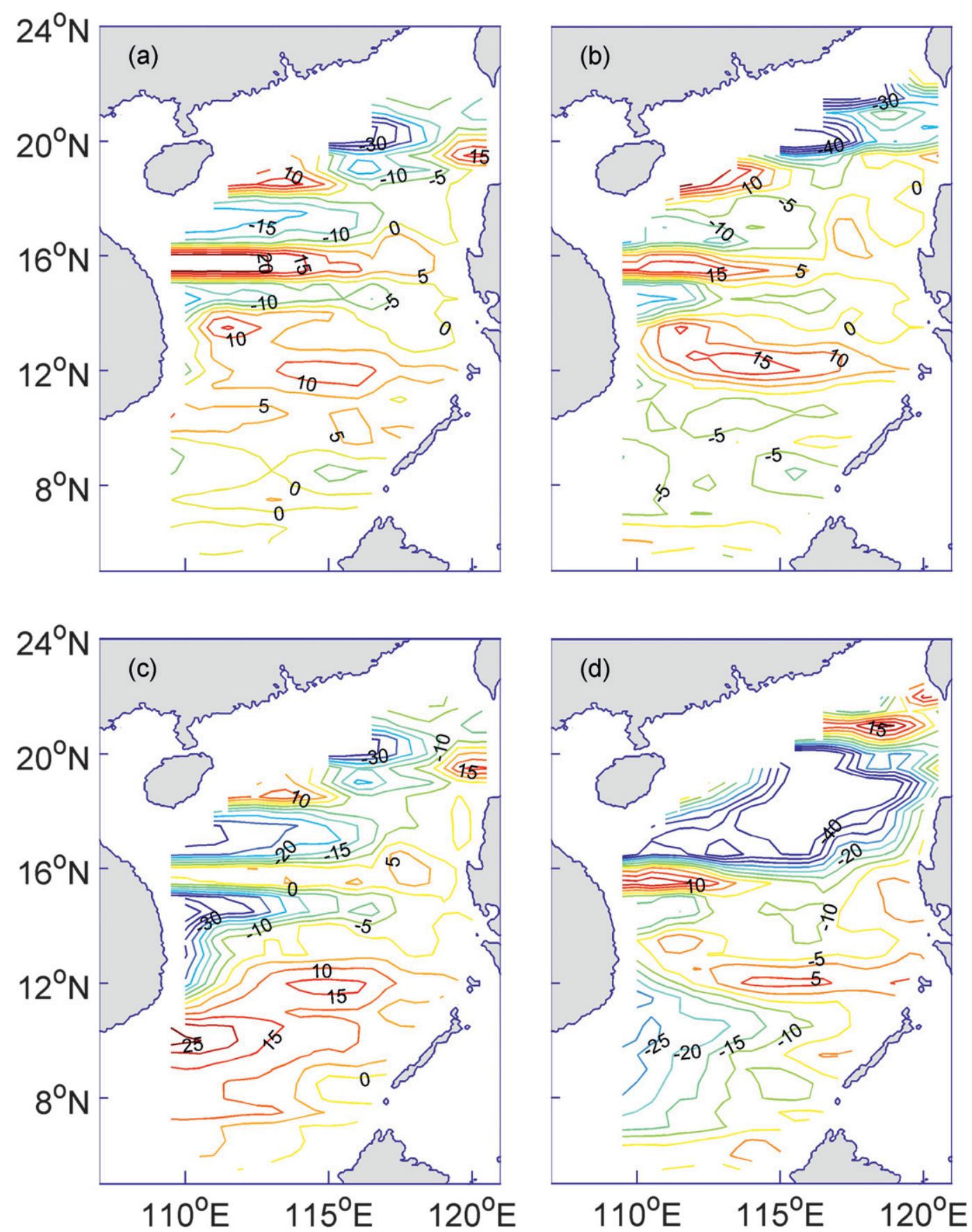

FIG. 8. The difference of thermocline depth (m) between case $3 \mathrm{~b}$ and case 1 in (a) summer and (b) winter; (c),(d) the thermocline depth anomaly in case $3 b$ for summer and winter, respectively.

while in winter they weaken the southern and northern parts of the winter cyclonic gyre by $20.0 \%$ and $31.6 \%$, respectively (Fig. 6d). These results are generally consistent with those discussed in section $3 \mathrm{~b}$.

We have also used the GDEM dataset to determine the vertical velocity at the thermocline base by the P-vector method. As shown in Figs. 7a and 7b, although strong downward velocity can be found in some regions, in particular along the southwestern SCS, the upward velocity is dominant in the vast areas of the SCS. Forced by the vertical mass fluxes, the additional interior flow (Figs. $8 \mathrm{a}$ and $8 \mathrm{~b}$ ) and resultant circulations (Figs. 8c and 8d) are quite similar to case $3 \mathrm{a}$. Comparing cases $3 \mathrm{a}$ and $3 \mathrm{~b}$ with the thermocline depth derived from GDEM, 

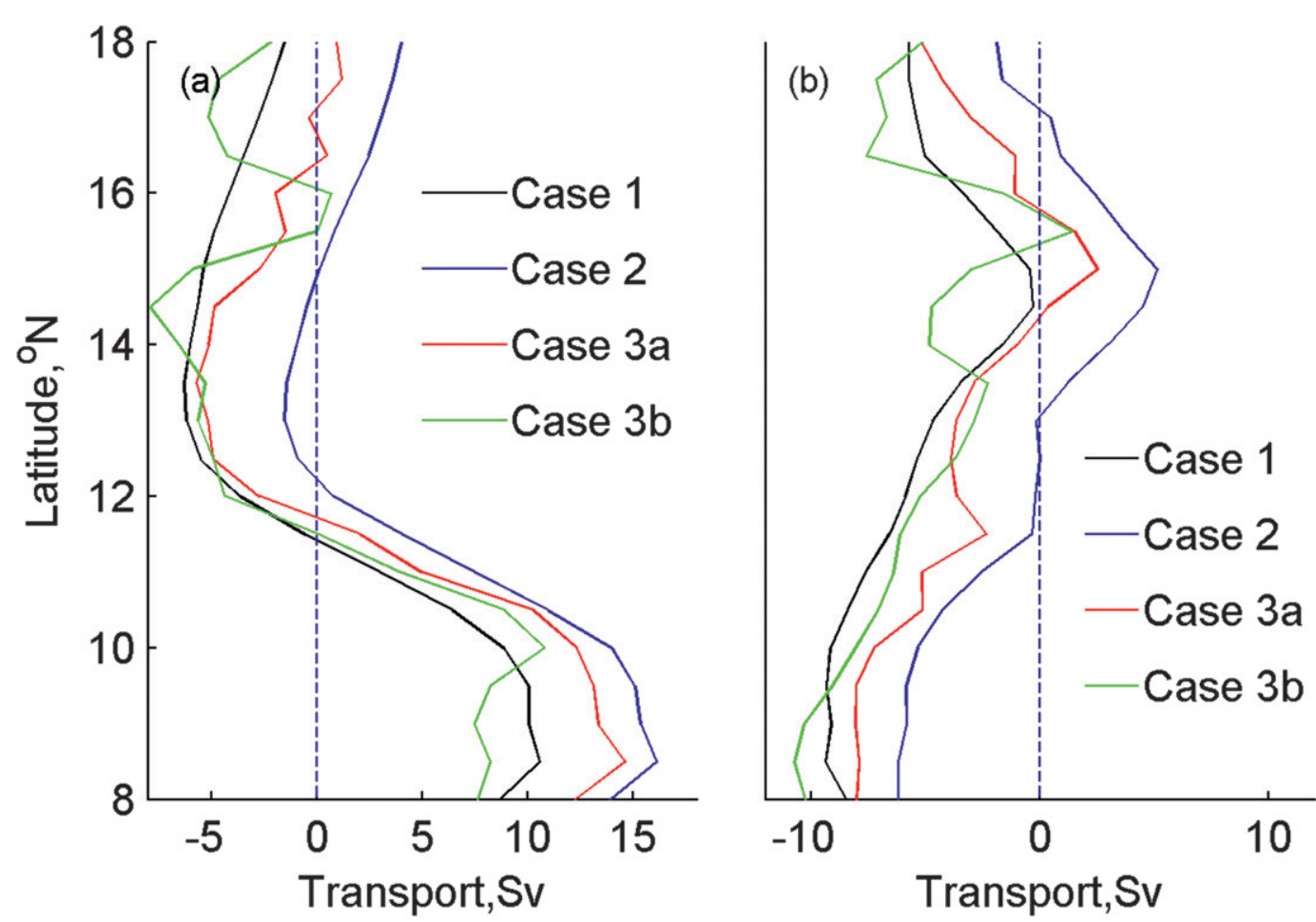

FIG. 9. Transport of the western boundary current (Sv): (a) summer; and (b) winter.

case $3 \mathrm{~b}$ is slightly more realistic than case $3 \mathrm{a}$. The spatial correlation coefficients between the simulations and observations are $0.39(0.36)$ and $0.42(0.37)$ in summer (winter) for the cases $3 \mathrm{a}$ and $3 \mathrm{~b}$, respectively. Table 2 also lists the contribution of the thermohaline circulation to the upper layer ocean for these cases.

\section{d. Western boundary currents}

Western boundary currents play important roles in the circulation system. They balance the zonally integrated interior meridional fluxes; thus, these currents can be used as an index for the strength of the gyre scale circulation. To evaluate the contribution of thermohaline circulation to the upper ocean circulation, we show the western boundary current transports for three experiments discussed above (Fig. 9). For the circulation forced by Ekman pumping only, in the winter season there is a southward jet flowing along the entire western boundary; in the summer season there is a northward jet flowing along the western boundary in the southern SCS and a southward one in the northern SCS. The basic circulation patterns are consistent with the results obtained from previous studies.

By including the abyssal uniform upwelling inferred from the Luzon transport (Case 2), the northward jet in the southern SCS is intensified and the southward jet in the northern SCS is weakened in summer (Fig. 6a), which is associated with the interior circulation change described in section 3b. In winter, the southern and northern parts of the southward jet in the SCS are weakened (Fig. 6b). For the case of nonuniform upwelling (cases 3a and $3 \mathrm{~b}$ ), the resulting changes in the western boundary transport are somewhat similar to that obtained in case 2 . Overall, the western boundary transport obtained from cases $3 \mathrm{a}$ and $3 \mathrm{~b}$ lies between those obtained from case 1 and case 2 . Note that there are slight differences between $3 \mathrm{a}$ and $3 \mathrm{~b}$, indicating that the downwelling flux also can regulate the upper layer circulation.

The mean transports of the western boundary current for these three experiments are listed in Table 3. Overall, the western boundary current transport in the southern SCS is larger than that in the northern SCS. By including the upwelling associated with the thermohaline circulation, the northward western boundary current in the southern SCS is intensified and the southward western boundary current in the northern SCS is weakened in summer, while both southern and northern parts of the western boundary current in the SCS are weakened in winter. Quantitatively, using Ekman pumping forcing run as a reference, the northward (southward) western boundary current transport in the southern (northern) SCS is intensified (reduced) by about $21.9 \%-31.8 \%$ $(32.4 \%-76.1 \%)$ in the other two experiments in summer, while the transport of southern (northern) part of 
TABLE 3. Western boundary current transport (Sv), the values in parentheses represent the contribution of the thermohaline circulation to the upper-layer ocean relative to case 1).

\begin{tabular}{llcccc}
\hline \hline & & Case 1 & Case 2 & Case 3a & Case 3b \\
\hline \multirow{2}{*}{ Summer } & North & -4.41 & $-1.06(-76.1 \%)$ & $-3.49(-38.4 \%)$ & $-2.98(-32.4 \%)$ \\
& South & 8.24 & $10.86(31.8 \%)$ & $10.37(25.9 \%)$ & $10.04(21.9 \%)$ \\
\multirow{2}{*}{ Winter } & North & -4.47 & $-1.60(-64.3 \%)$ & $-2.90(-35.2 \%)$ & $-2.86(-36.1 \%)$ \\
& South & -5.98 & $-3.68(-38.4 \%)$ & $-5.16(-14.0 \%)$ & $-5.19(-13.2 \%)$ \\
\hline
\end{tabular}

the SCS is reduced by about $13.2 \%-38.4 \%(35.2 \%-$ $64.3 \%$ ) in winter. As shown in Table 3, the contribution of the thermohaline circulation to the western boundary current transport in the northern SCS is larger than in the southern SCS for both summer and winter seasons.

\section{Conclusions and discussion}

Based on an idealized reduced gravity model forced by Ekman pumping and upwelling of deep water, we find that the vortex squashing due to motions of deep water can induce an anticyclonic circulation component in the upper layer of the SCS. As a result, in summer the cyclonic gyre in the northern SCS is weakened and the anticyclonic gyre in the southern SCS is intensified; while in winter both the cyclonic gyres in the southern and northern SCS are weakened. Accordingly, in summer the northward western boundary current in the southern SCS is intensified and the southward western boundary current in the northern SCS is weakened; while in winter both southern and northern parts of the western boundary currents in the SCS are weakened.

The interior circulation as well as the western boundary current transport in the model shows that the thermohaline circulation can strongly affect the upper-layer circulation, as compared to the circulation driven by Ekman pumping only. Furthermore, the model results reveal that the contribution in the northern SCS is larger than that in the southern SCS. The quantitative comparisons shown in Tables 2 and 3 suggest that, in order to understand the upper layer circulation in the SCS, the effects of the thermohaline circulation must be taken into consideration because the upwelling velocity from the deep part of the SCS is on the same order of magnitude as the typical Ekman pumping velocity.

Although our model is able to capture the essential dynamics of the SCS circulation, it is too idealized to offer a complete dynamical picture of the SCS. In addition, the upwelling velocity from the deep ocean calculated in this paper can only serve as a rough estimate. Although there are many methods to estimate the upwelling rate (for example, Kuo and Veronis 1973; Stuiver et al. 1983; Robbins and Toole 1997), they are not consistent with one another. These estimations are open to criticism and are somewhat questionable (Whitworth et al. 1999). Further study including more complete dynamics and realistic upwelling velocity should be helpful for understanding the relationship between the upper layer circulation and the deep circulation of the SCS.

This study is our first attempt at a quantitative description of the circulation in the upper ocean of the SCS, subject to the wind stress forcing as well as the dynamic influence of the thermohaline circulation in the deep part of the ocean. Becaue of the idealization used here, the results we obtained should be treated with caution. Nevertheless, we hope that our study will stimulate interest in exploring the dynamic relation between winddriven and thermohaline circulation in the ocean. In addition, the water mass transformation associated with the tide-driven diapycnal mixing inside the SCS may contribute to the water mass transformation within the entire North Pacific Ocean; thus, our study may also be useful for understanding the thermohaline exchange between marginal seas and the open oceans.

Acknowledgments. G. Wang is supported by the National Science Foundation of China (NSFC Grants 41125019, 40725017, and 40976017). D. Chen is supported by grants from the Ministry of Science and Technology (2010DFA21012), the State Oceanic Administration (201105018), and the NSFC (91128204). ECCO model output was provided by the group of Dr. Yiqun Qi from the South China Sea Institute of Oceanography, CAS. Suggestions by two anonymous reviewers helped us to greatly improve the presentation of this paper.

\section{REFERENCES}

Broecker, W. S., W. C. Patzert, J. R. Toggweiler, and M. Stuvier, 1986: Hydrography, chemistry, and radioisotopes in the southeast Asian basin. J. Geophys. Res., 91 (C12), 14 34514354.

Cai, S. Q., J. L. Su, Z. J. Gan, and Q. Y. Liu, 2002: The numerical study of the South China Sea upper circulation characteristics and its dynamic mechanism in winter. Cont. Shelf Res., 22, 2247-2264.

Cardona, Y., and A. Bracco, 2012: Enhanced vertical mixing within mesoscale eddies due to high frequency winds in the South China Sea. Ocean Modell., 42, 1-15.

Carnes, M. R., 2009: Description and evaluation of GDEM-V3.0. NRL Rep. NRL/MR/ 7330-09-9165, 27 pp. 
Chu, P. C., 1995: P-vector method for determining absolute velocity from hydrographic data. J. Mar. Technol. Soc., 29, 3-14. , and G. Wang, 2003: Seasonal variability of thermohaline front in the central South China Sea. J. Oceanogr., 59, 65-78.

Guan, Y. P., and R. X. Huang, 2008: Stommel's box model of thermohaline circulation revisited - The role of mechanical energy supporting mixing and the wind-driven gyration. J. Phys. Oceanogr., 38, 909-917.

Hautala, S. L., and S. C. Riser, 1989: A simple model of abyssal circulation including effects of wind, buoyancy and topography. J. Phys. Oceanogr., 19, 596-611.

Huang, R. X., 1993: A two-level model for the wind and buoyancyforced circulation. J. Phys. Oceanogr., 23, 104-115.

- 2010: Ocean Circulation, Wind-Driven and Thermohaline Processes. Cambridge University Press, 806 pp.

Jayne, S. R., and L. C. St. Laurent, 2001: Parameterizing tidal dissipation over rough topography. Geophys. Res. Lett., 28, 811-814.

Kuo, H. H., and G. Veronis, 1973: The use of oxygen as a test for an abyssal circulation model. Deep-Sea Res., 20, 871-888.

Li, L., and T. Qu, 2006: Thermohaline circulation in the deep South China Sea basin inferred from oxygen distributions. J. Geophys. Res., 111, C05017, doi:10.1029/2005JC003164.

Liu, Z. Y., H. J. Yang, and Q. Y. Liu, 2001: Regional dynamics of seasonal variability in the South China Sea. J. Phys. Oceanogr., 31, 272-284.

Luyten, J. R., and H. Stommel, 1986: Gyres driven by combined wind and buoyancy flux. J. Phys. Oceanogr., 16, 1551-1560.

Pedlosky, J., 1986: The buoyancy and wind-driven ventilated thermocline. J. Phys. Oceanogr., 16, 1077-1087.

Qu, T., 2000: Upper-layer circulation in the South China Sea. J. Phys. Oceanogr., 30, 1450-1460.

_ J. B. Girton, and J. A. Whitehead, 2006: Deep-water overflow through Luzon Strait. J. Geophys. Res., 111, C01002, doi:10.1029/ 2005JC003139.

Robbins, P. E., and J. M. Toole, 1997: The dissolved silica budget as a constraint on the meridional overturning circulation in the Indian Ocean. Deep-Sea Res., 41, 143-168.
Stommel, H., and A. B. Arons, 1960: On the abyssal circulation of the world ocean.-II. An idealized model of the circulation pattern and amplitude in oceanic basins. Deep-Sea Res., 6, 217-233.

Stuiver, M., P. D. Quay, and H. G. Ostlund, 1983: Abyssal water carbon-14 distribution and the age of the world oceans. Science, 219, 849-851.

Tian, J., Q. Yang, X. Liang, L. Xie, D. Hu, F. Wang, and T. Qu, 2006: Observation of Luzon Strait transport. Geophys. Res. Lett., 33, L19607, doi:10.1029/2006GL026272.

,-- , and W. Zhao, 2009: Enhanced diapycnal mixing in the South China Sea. J. Phys. Oceanogr., 39, 3191-3203.

Tong, J. Q., F. H. Lei, Q. W. Mao, and Y. Q. Qi, 2010: Tidal energy fluxes and dissipation in the South China Sea without considering tide-generated potential energy. J. Trop. Oceanogr., 29, 1-9.

Wang, G., D. Chen, and J. L. Su, 2008: Winter eddy genesis in the eastern South China Sea due to orographic wind jets. J. Phys. Oceanogr., 38, 726-732.

_ Z Z. Ling, and C. Wang, 2009: Influence of tropical cyclones on seasonal ocean circulation in the South China Sea. J. Geophys. Res., 114, C10022, doi:10.1029/2009JC005302.

— S.-P. Xie, T. Qu, and R. X. Huang, 2011: Deep South China Sea circulation. Geophys. Res. Lett., 38, L05601, doi:10.1029/ 2010 GL046626.

Wang, W., and R. X. Huang, 2004a: Wind energy input to the Ekman Layer. J. Phys. Oceanogr., 34, 1267-1275.

_ and $-2004 \mathrm{~b}$ : Wind energy input to the surface waves. J. Phys. Oceanogr., 34, 1276-1280.

Whitworth, T., III, B. A. Warren, W. D. Nowlin Jr., S. B. Rutz, R. D. Pillsbury, and M. I. Moore, 1999: On the deep western-boundary current in the Southwest Pacific basin. Prog. Oceanogr., 43, 1-54.

Wyrtki, K., 1961: Physical oceanography of the Southeast Asian waters. University of California NAGA Rep. 2, 195 pp.

Xie, S.-P., Q. Xie, D. X. Wang, and W. T. Liu, 2003: Summer upwelling in the South China Sea and its role in regional climate variations. J. Geophys. Res., 108, 3261, doi:10.1029/ 2003JC001867. 